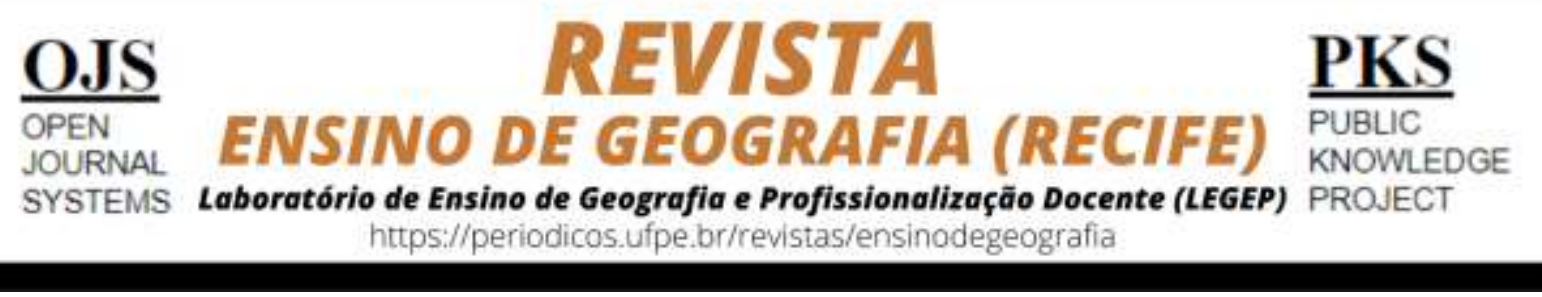

\title{
EXCURSÕES E AULA DE CAMPO EM GEOGRAFIA: UM OLHAR DIFERENTE SOBRE O SEMIÁRIDO
}

\author{
Thiago dos Santos Dantas $1^{1}$, Joel Maciel Pereira Cordeiro ${ }^{2}$
}

\begin{abstract}
${ }^{1}$ Universidade Estadual da Paraíba. E-mail: thiagodossantosdantas@ gmail.com - ORCID iD: http://orcid.org/0000-0002-4798-3484

${ }^{1}$ Universidade Estadual da Paraíba. E-mail: joelmpcordeiro@yahoo.com.br - ORCID iD: http://orcid.org/00000001-9833-0822
\end{abstract}

Artigo recebido em 26/03/2020 e aceito em 03/04/2020

\begin{abstract}
RESUMO
O semiárido nordestino envolve uma área de aproximadamente $1.120 .000 \mathrm{~km}^{2}$ distribuído entre 1.262 municípios. Embora seja tratado muitas vezes como ambiente seco e adverso, o semiárido apresenta uma ampla diversidade de elementos naturais, histórico-culturais e áreas economicamente desenvolvidas. O presente trabalho tem como objetivo demonstrar a relação sociedade-natureza e a diversidade paisagística natural e cultural do semiárido a partir de excursões envolvendo aulas de campo. A excursão envolveu alunos e professores de graduação em geografia (licenciatura plena). Foram visitados os municípios de Juazeirinho, Patos e Sousa na Paraíba e diversas temáticas foram discutidas de forma prática, como vegetação da caatinga, clima, geologia, geomorfologia, paleontologia, recursos hídricos e economia do semiárido. As atividades práticas de excursões envolvendo aulas de campo se demonstraram de fundamental importância para a formação profissional do licenciado em geografia, permitindo o desenvolvimento de novos conceitos, novos olhares e pensamentos críticos sobre diversas temáticas envolvendo o semiárido nordestino.
\end{abstract}

Palavras-chave: Análise da paisagem; Caatinga; Estereótipos regionais; Nordeste; Trabalho de campo.

\section{EXCURSIONS AND FIELD CLASS IN GEOGRAPHY: A DIFFERENT VIEW ABOUT THE SEMI-ARID}

\begin{abstract}
The semiarid has approximately $1,120,000 \mathrm{~km}^{2}$, distributed among 1,262 municipalities. Although it is often treated as a dry and adverse environment, the semiarid has a wide diversity of natural, historical and cultural elements, and economically developed areas. The present work aims to demonstrate the relationship between society and nature, and the natural and cultural landscape diversity of the semiarid through excursions involving field classes. The excursion involved students and teachers of geography graduation (full degree). The municipalities of Juazeirinho, Patos and Sousa, municipalities of Paraíba state, Brazil, were visited. Several subjects were discussed in a practical way, such as Caatinga, climate, geology, geomorphology, paleontology, water resources and economy of semiarid. The practical activities of excursions involving field classes proved to be of fundamental importance for the professional training in geography, allowing the development of new concepts, new perspectives and critical thoughts of various themes involving the Northeastern semiarid.
\end{abstract}

Keywords: Landscape analysis; Caatinga; Regional stereotypes; Northeastern; Fieldwork. 


\section{INTRODUÇÃO}

Ao longo da história de ocupação do semiárido nordestino a criação pecuária e o desenvolvimento de agricultura de subsistência predominaram na produção do espaço regional (ANDRADE, 2005; SILVA et al., 2017). Nas últimas décadas, outras possibilidades de desenvolvimento de atividades econômicas vêm sendo ampliadas, contribuindo para uma melhoria na qualidade de vida da população (SILVA et al., 2017; SOUSA et al., 2017; VENTURA et al., 2019). Contudo, o discurso midiático, por vezes, ainda propaga uma visão estereotipada da região, como um ambiente seco e adverso, na qual a população não tem acesso à tecnologia e saneamento, com sistema precário de transporte e rudimentares práticas agrícolas (LEITÃO \& SANTOS, 2012; SILVA \& MASSUCHIN, 2019).

No processo de formação docente em geografia determinadas metodologias de ensino devem ser empregadas para o efetivo desenvolvimento de diversas habilidades nos estudantes, incluindo a análise crítica dos fenômenos espaciais (MARTINS, 2017). Além disso, enfatizase que a sociedade no contexto atual necessita de professores que sejam criativos, com visão científica do mundo, que procurem independentemente novos conhecimentos geográficos e apliquem diferentes reflexões sobre temáticas abrangentes (MIZAMBAEVA \& BAIMYRZAEV, 2019).

As atividades de excursão e aula de campo envolvendo abordagens interdisciplinares com observação e leitura da paisagem e análise do espaço geográfico permitem a discussão de diversas temáticas importantes para a formação do profissional de geografia (LAMBERT \& REISS, 2016; TRICART, 2017; JESUS \& SANTOS, 2019). O trabalho de campo em forma de excursão permite, além disso, desenvolver com os estudantes a problematização de diversas questões, além de refletir os fenômenos observados, constituindo assim em importante ferramenta para o processo de desenvolvimento crítico dos alunos (ALENTEJANO \& ROCHA-LEÃO, 2006).

Aulas de campo em forma de excursões no semiárido nordestino podem destacar questões e conteúdo de forma interdisciplinar envolvendo diferentes componentes curriculares (GOMES et al., 2019). Além disso, podem favorecer o desenvolvimento de diversas habilidades fundamentais na formação do professor de geografia, especialmente a análise da paisagem, 
discussões de aspectos regionais (incluindo estereótipos midiáticos), a análise crítica do espaço geográfico e o entendimento da interação sociedade/natureza.

Desta forma, o presente trabalho tem como objetivo demonstrar a relação sociedadenatureza e a diversidade paisagística natural e cultural do semiárido a partir de excursões envolvendo aulas de campo. Discussões teóricas sobre diversos elementos relacionados à produção do espaço geográfico do semiárido foram estabelecidas, assim como a importância das atividades de campo para a formação geográfica e sua dinâmica no processo de ensinoaprendizagem. Estes elementos foram conciliados de forma integrada com a análise e descrição da realidade observada na aula de campo.

\section{PROCEDIMENTOS METODOLÓGICOS}

O desenvolvimento do trabalho foi realizado a partir de três pontos principais: 1) discussão teórica referente ao semiárido nordestino abrangendo sua natureza, evolução do espaço geográfico e questões ambientais; 2) discussão teórica sobre questões referentes à importância das atividades de campo para a formação geográfica no ensino superior; e 3) descrição de elementos observados no semiárido nordestino através de aula de campo em forma de excursão realizada por alunos e professores do curso de Licenciatura Plena em Geografia.

A região semiárida percorrida incluiu as mesorregiões do Agreste, Borborema e Sertão paraibano. No decorrer da excursão foram realizadas paradas em pontos estratégicos, com discussões e análises do espaço geográfico observado em determinados locais, especialmente nos municípios de Juazeirinho, Patos e Sousa na Paraíba. Nestes espaços eram realizadas análises da paisagem e explicações práticas sobre os elementos observados (geologia, geomorfologia, biogeografia, hidrografia, economia e sociedade).

\section{O SEMIÁRIDO NORDESTINO: NATUREZA, EVOLUÇÃO DO ESPAÇO GEOGRÁFICO E QUESTÕES AMBIENTAIS}

O semiárido nordestino compreende uma área de 1.128.697 km² distribuídos entre 1.262 municípios (SUDENE, 2018), caracterizado pelas altas temperaturas e baixas pluviosidades (abaixo de 800mm/ano) (MARENGO et al., 2011). Segundo Ab'Saber (1974) a ocorrência dessa semiaridez no semiárido nordestino é resultado da primazia das massas de ar estáveis empurradas na direção sudeste pelos alísios, originados pela ação do anticiclone do Atlântico 
Sul. A vegetação típica do semiárido nordestino é a caatinga, formada por espécies caducifólias espinhosas, cactáceas e bromeliáceas rupícolas (QUEIROZ et al., 2017). Apesar de sua rigidez climática, o semiárido nordestino se apresenta como uma das regiões mais populosas entre as áreas semidesérticas do globo terrestre (27.870.241 habitantes) (SUDENE, 2018), marcado, sobretudo, pelo processo histórico de ocupação de seu espaço geográfico.

No início do seu processo de ocupação, os rios constituíram as principais vias de penetração no semiárido, sobretudo pela facilidade de circulação e a disponibilidade da água que condicionaram a ocupação das margens fluviais e produziram o 'povoamento de ribeira', com instalação de grandes fazendas de gado (MOREIRA \& TARGINO, 1997; SILVA et al., 2017). O rebanho bovino foi um vetor inicial de desenvolvimento do semiárido e sua utilização era bastante variada, tanto no ramo alimentício (carne e leite), como na utilização para produção de vestimentas e de uma grande variedade de produtos e utensílios (ANDRADE, 2005). A agricultura era principalmente de subsistência e baseada no método tradicional de corte e queima (SILVA et al., 2017).

O sertão passou a se destacar no cultivo de algodão, que, ao lado da pecuária bovina, se tornaram os principais produtos da região em maior parte dos séculos XIX e XX (ANDRADE, 2005). Com a presença de uma pequena cultura alimentícia, produzida para subsistência da população, o sertão tinha três pilares econômicos: gado, algodão e culturas alimentares (MOREIRA e TARGINO, 1997; ANDRADE, 2005). Contudo, em meados da década de 1970, a produção algodoeira no semiárido entrou em declínio, sobretudo pelas plantações terem sido atacadas pelo bicudo, que inviabilizava a produção desta lavoura (ANDRADE, 2005). Nos últimos anos, problemas acentuados de irregularidades climáticas têm dificultado até mesmo a criação da pecuária bovina e produção de culturas alimentares na região (MARENGO et al., 2011).

Em relação a questões ambientais, o semiárido brasileiro apresenta parte significativa do seu território propício ao desenvolvimento do processo de desertificação. Este problema ambiental repercute na perda da capacidade biológica do solo, ocasionada principalmente pelo uso excessivo do mesmo com práticas agrícolas inadequadas e superpastoreio (TRAVASSOS et al., 2013; SILVA \& BARBOSA, 2017). O solo passa a apresentar-se estéril, sem capacidade para produção de pastagens e lavouras, além de apresentar ausência ou crescimento lento da vegetação nativa. Baixos índices pluviométricos ( $<600 \mathrm{~mm} / \mathrm{ano})$, temperaturas elevadas (acima de $27{ }^{\circ} \mathrm{C}$ ), déficit hídrico acentuado e alta densidade demográfica contribuem para agravar o 
processo (TRAVASSOS et al., 2013; SILVA \& BARBOSA, 2017). Tais elementos, portanto, fazem do semiárido uma área essencial para a adoção de estratégias de conservação ambiental e desenvolvimento sustentável.

O governo brasileiro nos últimos anos criou várias políticas para combater a desertificação de diversas áreas do semiárido, entre eles se destacando a criação do PAN-Brasil (Plano de Ação Nacional de Combate à Desertificação e Mitigação dos Efeitos da Seca) (BRASIL, 2004). Entre as medidas trabalhadas estão a redução da pobreza e da desigualdade, a ampliação sustentável da capacidade produtiva, e a preservação, conservação e manejo sustentável dos recursos naturais do semiárido. Aliada a estes fatores, diversas ações, como o cultivo de forragens e culturas alimentícias e resistentes à seca, a instalação de dessalinizadores, a transposição de águas do rio São Francisco, atividades de educação ambiental e conscientização realizada junto às comunidades locais, e auxílios de programas sociais têm possibilitado à população sobreviver no semiárido, mesmo com as adversidades existentes nesta região (SOUSA et al., 2017; SILVA et al., 2017; VENTURA et al., 2019).

\section{ATIVIDADES DE CAMPO EM GEOGRAFIA E SUA IMPORTÂNCIA PARA A FORMAÇÃO GEOGRÁFICA}

Ao longo da evolução da geografia como ciência, é reconhecido que o trabalho de campo desempenha um papel indispensável na pesquisa e formação do geógrafo (SUERTEGARAY, 2002; AZAMBUJA, 2012). Diversos autores confirmam que a percepção dos fenômenos espaciais, descrição de paisagens, desenvolvimento de análises probabilísticas, análise crítica e reflexiva de questões sociais e elementos culturais, e entendimento da organização regional e territorial são melhores entendidos através de trabalhos de campo (LAMBERT e REISS, 2016; TRICART, 2017; GOMES et al., 2019; JESUS e SANTOS, 2019).

Embora sejam baseadas no entendimento prático dos fenômenos espaciais, as atividades de campo em geografia envolvem diferentes abordagens didáticas e metodológicas e podem ser divididas normalmente em três formas: trabalho (ou pesquisa) de campo, aula de campo (ou estudo do meio) e excursões. O "trabalho de campo" constitui em uma etapa da realização de trabalhos acadêmicos que segue uma metodologia pré-estabelecida, envolvendo os procedimentos e materiais usados para alcançar os objetivos de uma pesquisa (SUERTEGARAY, 2002; TRICART, 2017). O trabalho de campo, embora também presente 
na educação básica, direciona-se especialmente para a pesquisa de estudantes de graduação e pós-graduação. A "aula de campo" fundamenta-se especialmente como continuação de uma aula em classe, onde são estabelecidas relações entre teoria e prática das temáticas abordadas (OLIVEIRA e ASSIS, 2009; CORDEIRO e OLIVEIRA, 2011). A aula de campo constitui em um recurso didático ou metodologia de ensino-aprendizagem (JESUS e SANTOS, 2019), sendo importante em todas as modalidades de ensino. Contudo, tem importância menos considerável no desenvolvimento de trabalhos e pesquisas acadêmicas. As "excursões" envolvem especialmente visitas e observações de determinados locais (geralmente pontos turísticos ou lugares estratégicos), onde os professores (ou mesmo guias turísticos) discursam diante dos estudantes sobre os elementos observados (ABRIL-SELLARÉ et al., 2019; SILVA e COUTINHO, 2019). As excursões normalmente são conciliadas com aulas de campo na graduação e pós-graduação, mas frequentemente são tratadas apenas como "passeio" na educação básica.

Embora não seja considerada importante para o desenvolvimento da pesquisa em geografia por gerar um conhecimento considerado fragmentado (LACOSTE, 2006), as excursões podem representar uma considerável contribuição para o processo de formação dos estudantes como professores e pesquisadores (ALENTEJANO e ROCHA-LEÃO, 2006). As excursões envolvendo aula de campo podem envolver diversas temáticas da geografia, como análises de padrões climáticos, análises geológicas e geomorfológicas, estudos sobre a economia e cultura de dada região, entre outros (COMPIANE e CARNEIRO, 1993; ABRILSELLARÉ et al., 2019; SILVA e COUTINHO, 2019). Estas atividades permitem fazer um "recorte" de determinado local e estudá-lo de infinitas maneiras. Esse pequeno "recorte" pode servir de escala para entender os fenômenos espaciais por completo (COMPIANE e CARNEIRO, 1993).

$\mathrm{Na}$ análise do espaço geográfico por meio de excursões é possível reunir informações físicas, culturais e ambientais, além da discussão do contexto histórico de ocupação daquele espaço e, mais além, realizar reflexões e interpretações sobre problemas ou situações observadas (SILVA e COUTINHO, 2019). Além disso, através das excursões, as imagens propagadas nos elementos midiáticos sobre determinada região podem ser confrontadas em uma realidade prática observável, permitindo estabelecer questionamentos e análises críticas sobre diferentes pontos de vista. 


\section{EXCURSÕES E AULA DE CAMPO: UMA EXPERIÊNCIA NO SEMIÁRIDO}

A excursão ao semiárido paraibano com explicações práticas teve início no município de Juazeirinho, Paraíba, mesorregião da Borborema, no qual foi destacada a vegetação de Caatinga. $\mathrm{Na}$ oportunidade foram discutidas as principais características desta vegetação, especialmente sua adaptação como mata estacional decidual, a presença de espinhos em suas plantas e a comum ocorrência de cactáceas e bromeliáceas rupícolas (Figura 1A). Em campo era observada sua composição florística (mandacaru, facheiro, pereiro, jurema, entre outras) e características gerais da vegetação formada por árvores e arbustos com galhos retorcidos. As habitações que havia no local apresentavam cisternas usadas pelos moradores para armazenar água de chuva e utilizá-la durante a época seca. As criações pecuárias eram formadas especialmente por rebanhos de caprinos (Figura 1B).

Prosseguindo a excursão, o segundo ponto de discussão prática realizou-se no município de Patos, onde se observava os inselbergs, resquícios de relevos antigos que se destacam na paisagem da Depressão Sertaneja (Figura 1C). Para Gomes et al. (2019), a observação prática da Depressão Sertaneja atua como importante elemento didático na compreensão dos processos geológicos e geomorfológicos das regiões semiáridas, onde é possível entender os fenômenos de aplainamento, como resposta morfoestrutural aos processos exógenos e destacados na paisagem devido à erosão diferencial. Ainda no município de Patos, os estudantes tiveram a oportunidade de observar um contraste de paradigmas sobre a região semiárida: a imagem de seca e escassez de água. De fato, as matérias que são veiculadas em vários jornais de alcance nacional historicamente retratam o semiárido reduzindo-o à seca, à presença de caveiras de gado, e de terra rachada (LEITÃO e SANTOS, 2012). Entretanto, no município de Patos é observado a existência de grandes açudes, como o Açude do Jatobá e o Açude da Farinha (Figura 1D), se percebendo a disponibilidade hídrica abundante em diversas áreas do semiárido.

No último ponto da excursão foi visitado o município de Sousa na Paraíba. Durante o percurso houve uma parada nas grandes plantações localizadas nas várzeas de Sousa, com cultivo de monocultura irrigada, controlada em parte por empresas transnacionais. Em determinados locais encontravam-se assentamentos da reforma agrária, carentes de infraestrutura e voltados ao cultivo de agricultura de subsistência. As terras das várzeas de Sousa são férteis e repletas de nutrientes, praticamente sendo uma das melhores regiões para 
plantio dentro do semiárido paraibano (CORRÊA et al., 2003). O local também é o ponto final do canal da redenção, obra criada para transportar água do açude Coremas - Mãe d’Água até as várzeas de Sousa, com o intuito de garantir sustento hídrico para população ao longo do canal. Porém devido ao desvio de água para irrigação ao longo do canal, muitas famílias acabam se tornando carentes deste recurso.

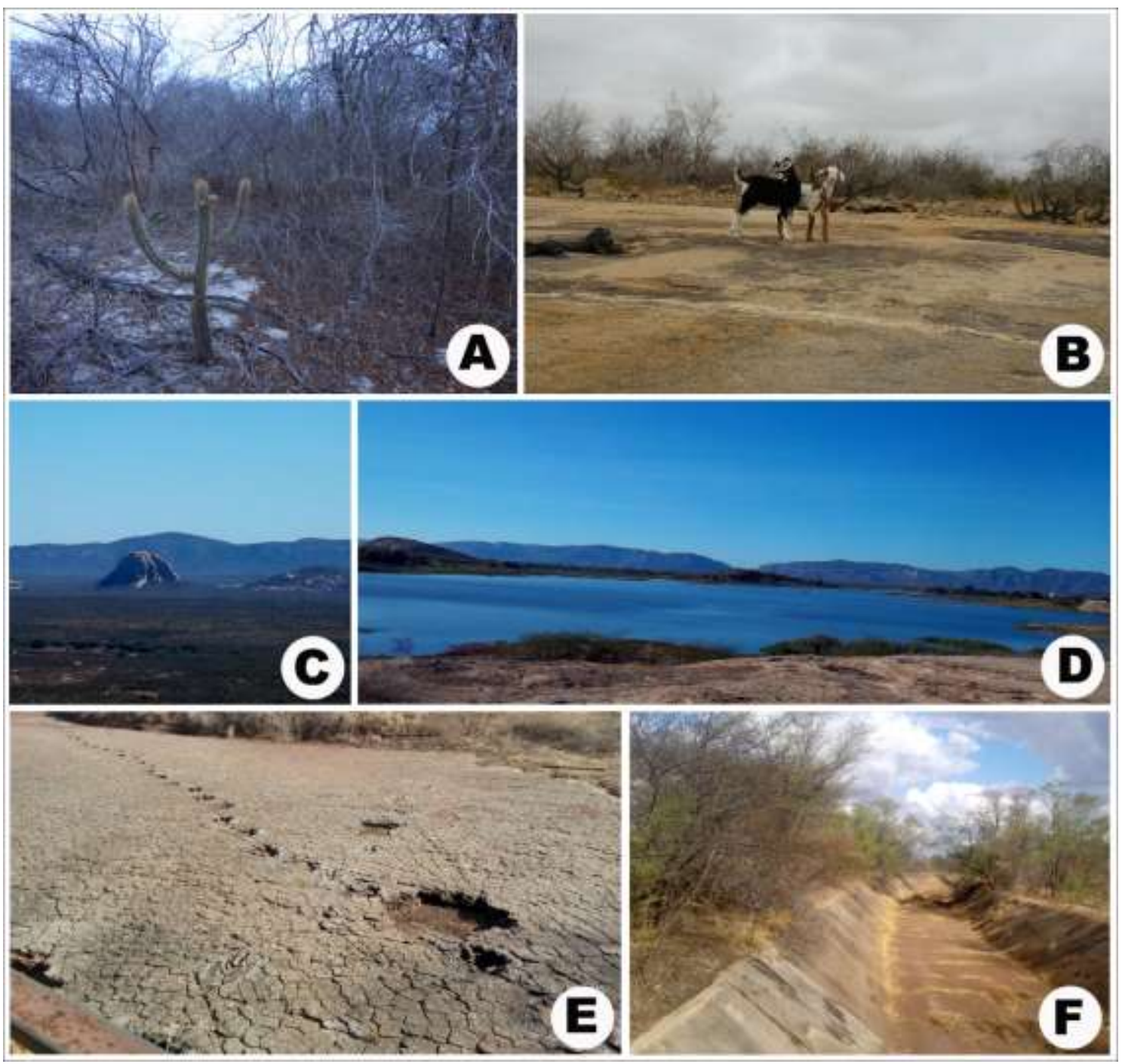

Figura 1. Elementos da paisagem do semiárido paraibano: A. Aspecto da vegetação de caatinga; B. Criação de caprinos; C. Depressão Sertaneja com destaque de inselberg; D. Grandes açudes em região semiárida (Açude da Farinha, Patos, PB); E. Trilhas de pegadas de dinossauros (Vale dos Dinossauros, Sousa, PB); F. Canal de Alívio (Vale dos Dinossauros, Sousa, PB). Fonte: arquivo dos autores

O seguinte ponto de explicação prática se deu no Açude São Gonçalo, município de Sousa, que se localiza na bacia do Rio Piranhas. O mesmo é um reservatório hídrico construído na década de 70. Criado na intenção de armazenar a água do rio no período chuvoso, para ser utilizado durante a seca para a sobrevivência da população e a irrigação das plantações 
existentes na região. Neste local os alunos, mesmo sem terem domínio na área, puderam perceber conceitos da geomorfologia, as formas do local onde eles se encontravam e o relevo encontrado em volta do reservatório. Era notável a percepção que o açude era praticamente natural, situado em uma área côncava, no qual foi necessário o simples planejamento da obra na construção do chamado "Balde do Açude", que geralmente é a área construída majoritariamente pelo ser humano.

O último ponto da excursão constituiu na visita ao parque natural "Vale dos dinossauros", um dos mais importantes sítios paleontológicos reconhecido pelas pegadas deixadas há milhões de anos pelos dinossauros (LEONARDI e CARVALHO, 2002). No local se encontram as maiores trilhas de pegadas de dinossauro do mundo (53 pegadas) (Figura 1E). Os icnofósseis da trilha principal pertencem a uma espécie do grupo iguanodontiana, além de algumas pistas de terópodes menores (SANTOS et al., 2016). De início foi visitado o museu local, onde estão disponíveis informações visuais, paleopaisagens, fósseis, icnofósseis, materiais utilizados por paleontólogos e informações gerais sobre o vale. No segundo momento houve uma explicação no decorrer do percurso, onde os alunos puderam fazer observações importantes sobre a vegetação e o clima típico da região semiárida. Durante o percurso passou se pelo "canal de alívio" (Figura 1F), uma espécie de córrego de cerca de 1000 m criado para auxiliar no escoamento da água do rio do peixe, que em tempos de enchente desgastavam as pegadas.

Somando todas as experiências de aula de campo no semiárido paraibano foi possível perceber os diversos contrastes existentes na região, hora apresentando locais ricos em elementos naturais favoráveis ao turismo, elevada disponibilidade de recursos hídricos e desenvolvimento econômico, hora apresentando locais pouco povoados e carentes de infraestrutura. De forma geral, a excursão permitiu a aquisição de diversos conhecimentos sobre o semiárido, criando conceitos e novos olhares sobre esta região, muitos dos quais diferentes dos apresentados em fontes midiáticas.

A aquisição de conceitos e visões diferentes do espaço geográfico proporcionado pela excursão com aulas de campo constituiu, de forma geral, indispensáveis para o desenvolvimento crítico e reflexivo do alunado. Assim, as excursões são de fundamental importância para a formação de professores de geografia, onde o observar, discutir, analisar e entender a realidade concreta observada, além de trazer conhecimento, também traz experiências que deverão ser aplicadas em sala de aula na educação básica. 


\section{CONSIDERAÇÕES FINAIS}

O semiárido nordestino é um lugar repleto de recursos naturais, elementos históricoculturais e de contrastes sociais, que ainda necessitam ser mais bem estudados e discutidos. Uma região que pode se apresentar rica, mas que na maioria das vezes é repassada de forma estereotipada pelas fontes midiáticas nacionais.

Por meio de excursões envolvendo aulas de campo no semiárido paraibano, alunos de licenciatura em geografia conseguiram se colocar dentro daquela realidade estudada. Tais atividades permitiram discussões de temáticas envolvendo hidrografia, biogeografia, geomorfologia, geologia, economia e sociedade do semiárido.

As excursões com aulas de campo, de forma geral, favorecem a aquisição de novos conhecimentos e novas reflexões sobre as temáticas abordadas, contribuindo como recurso importante para a formação do geógrafo. Além disso, permite o entendimento de diferentes realidades que podem ser usadas de forma crítica e reflexiva em sua atuação profissional na educação básica.

\section{REFERÊNCIAS}

AB'SABER, A. N. O domínio morfoclimático semi-árido das caatingas brasileiras. Geomorfologia, n. 43, p. 1-39, 1974.

ABRIL-SELLARÉS, M.; CRIADO, M. C. A.; SÁNCHEZ-FERNÁNDEZ, M. D. Análisis del viaje como uno de los ejes transformadores del proceso educativo. Universitas, v. 30, p. 6378, 2019.

ALENTEJANO, P. R. R.; ROCHA-LEÃO, O. M. Trabalho de campo: uma ferramenta essencial para os geógrafos ou um instrumento banalizado? Boletim Paulista de Geografia, v. 84, p. 51-67, 2006.

ANDRADE, M. C. A terra e o homem no Nordeste: contribuição ao estudo da questão agrária no Nordeste. 8 ed. São Paulo: Cortez, 2005. 336p.

AZAMBUJA, L. D. Trabalho de campo e ensino de Geografia. Geosul, Florianópolis, v. 27, n. 54, p. 181-195, 2002. 
BRASIL. Programa de Ação Nacional de Combate à Desertificação e Mitigação dos Efeitos da Seca/PAN-Brasil. Brasília (DF): Ministério do Meio Ambiente/Secretaria de Recursos Hídricos, 2004. 214p.

COMPIANI, M.; CARNEIRO, C. D. R. Os papéis didáticos das excursões geológicas. Enseñanza de las Ciencias de la Tierra, v. 1, n. 2, p. 90-97, 1993.

CORDEIRO, J. M. P.; OLIVEIRA, A. G. A aula de campo em geografia e suas contribuições para o processo de ensino-aprendizagem na escola. Geografia (Londrina), v. 20, n. 2, p. 99114, 2011.

CORRÊA, M. M.; KER, J. C.; MENDONÇA, E. S.; RUIZ, H. A.; BASTOS, R. S. Atributos físicos, químicos e mineralógicos de solos da região das várzeas de Sousa (PB). Revista Brasileira de Ciência do Solo, v. 27, n. 2, p. 311-324, 2003.

GOMES, J. F.; LUNA, V. F.; SILVA, M. O.; RIBEIRO, S. C. A importância da aula de campo como metodologia de ensino de Geomorfologia do Semiárido: relato de experiência nos sertões da Paraíba e do Rio Grande do Norte. Revista da Casa da Geografia de Sobral (RCGS), v. 21, n. 2, p. 784-794, 2019.

JESUS, M. C. S.; SANTOS, M. F. A aula de campo no ensino da geografia: experiências cotidianas na cidade para construção de aprendizagens. Revista Ensino de Geografia (Recife), v. 2, n. 1, p. 186-197, 2019.

LACOSTE, Y. A pesquisa e o trabalho de campo: um problema político para os pesquisadores, estudantes e cidadãos. Boletim Paulista de Geografia, v. 84, p. 77-92, 2006.

LAMBERT, D.; REISS, M. J. The place of fieldwork in geography qualifications. Geography, v. 101, n. 1, p. 28-34, 2016.

LEITÃO, J. A.; SANTOS, M. S. T. Imagem jornalística e representações sociais: a imagem dos Sertões. Intercom (São Paulo), v. 35, n. 1, p. 133-155, 2012.

LEONARDI, G.; CARVALHO, I. S. Icnofósseis da Bacia do Rio do Peixe, PB: o mais marcante registro de pegadas de dinossauros do Brasil. In: SCHOBBENHAUS, C.; CAMPOS, D. A.; QUEIROZ, E. T.; WINGE M.; BERBERT-BORN, M. L. C. (edts.). Sítios geológicos e paleontológicos do Brasil. Departamento Nacional de Produção Mineral (DNPM), 2002. p. 101-111.

MARENGO, J. A.; ALVES, L. M.; BESERRA, E. A.; LACERDA, F. F. Variabilidade e mudanças climáticas no semiárido brasileiro. In: MEDEIROS, S. S.; GHEYI, H. R.; GALVÃO, 
C. O.; PAZ, V. P. S. (Orgs.). Recursos hídricos em Regiões Áridas e Semiáridas. INSA, Campina Grande, pp. 383- 416, 2011.

MARTIN, R. E. M. W. Os desafios na construção dos saberes docentes do professor de geografia. Linguagens, Educação e Sociedade, v. 1, n. 33, p. 63-78, 2017.

MIZAMBAEVA, F. K.; BAIMYRZAEV, K. M. Conditions for the formation of professional competence of an intending geography teacher. Revista Espacios, v. 40, n. 09, 2019.

MOREIRA, E. R. F.; TARGINO, I. Capítulos de geografia agrária da Paraíba. Editora Universitária/UFPB: João Pessoa, 1997. 332p.

OLIVEIRA, C. D. M.; ASSIS, R. J. S. Travessias da aula em campo na geografia escolar: a necessidade convertida para além da fábula. Educação e Pesquisa, v. 35, n. 1, p. 195-209, 2009.

QUEIROZ, L. P.; CARDOSO, D.; FERNANDES, M. F.; MORO, M. F. Diversity and evolution of flowering plants of the Caatinga domain. In: SILVA, J. M. C.; LEAL, I. R.; TABARELLI, M. (edt.). Caatinga: the largest tropical dry forest region in South America. Springer International Publishing: Amsterdam, 2017, p. 23-63.

SANTOS, W. F. S.; CARVALHO, I. S.; BRILHA, J. B.; LEONARDI, G. Inventory and assessment of palaeontological sites in the Sousa Basin (Paraíba, Brazil): preliminary study to evaluate the potential of the area to become a geopark. Geoheritage, v. 8, n. 4, p. 315-332, 2016.

SILVA, J. M. C.; BARBOSA, L. C. F.; LEAL, I. R.; TABARELli, M. The Caatinga: understanding the challenges. In: SILVA, J. M. C.; LEAL, I. R.; TABARELLI, M. (edt.). Caatinga: the largest tropical dry forest region in South America. Springer International Publishing: Amsterdam, 2017, p. 03-19.

SILVA, J. M. C.; BARBOSA, L. C. F. Impact of human activities on the Caatinga. In: SILVA, J. M. C.; LEAL, I. R.; TABARELLI, M. (edt.). Caatinga: the largest tropical dry forest region in South America. Springer International Publishing: Amsterdam, 2017, p. 359-368.

SILVA, E. J.; COUTINHO, D. J. G. A excursão geográfica como recurso didático no ensino de geografia. Brazilian Journal of Development, v. 5, n. 12, p. 31667-31675, 2019.

SILVA, S. D. R.; MASSUCHIN, M. G. Construção do Nordeste no telejornalismo: um estudo do Jornal Hoje. Revista Extraprensa, v. 13, n. 1, p. 185-207, 2019. 
SILVA, J. M. C.; BARBOSA, L. C. F.; LEAL, I. R.; TABARELLI, M. The Caatinga: understanding the challenges. In: SILVA, J. M. C.; LEAL, I. R.; TABARELLI, M. (edt.). Caatinga: the largest tropical dry forest region in South America. Springer International Publishing: Amsterdam, 2017, p. 03-19.

SOUSA, J. D.; LIMA, D. C.; BRITO, F. C. S.; MEDEIROS, A. P.; PAIVA, A. C. C.; MARACAJA, P. B. O desenvolvimento da região Nordeste: uma abordagem econômica e ambiental. Revista Brasileira de Gestão Ambiental, v. 11, n. 1, p. 42-48, 2017.

SUDENE - SUPERINTENDÊNCIA DE DESENVOLVIMENTO DO NORDESTE. Nova delimitação Semiárido. Resolução CONDEL no 107, de 27/07/2017 e nº 115, de 23/11/2017. Ministério da Integração Nacional, 2018. Disponível em: < http://www.sudene.gov.br > Acesso em: 03 Novembro 2019.

SUERTEGARAY, D. M. A. Pesquisa de campo em geografia. GEOgraphia, v. 4, n. 7, p. 64$68,2002$.

TRAVASSOS, I. S.; SOUZA, B. I.; SILVA, A. B. Secas, desertificação e políticas públicas no semiárido nordestino brasileiro. Okara: Geografia em debate, v. 7, n. 1, p. 147-164, 2013.

TRICART, J. O campo na dialética da geografia. GEOUSP: Espaço e Tempo (Online), v. 21, n. 1, p. 305-314, 2017.

VENTURA, A. C.; GARCIA, L. F.; ANDRADE, J. C. S. O potencial das tecnologias sociais de convivência com o semiárido para a geração de sinergia entre mitigação e adaptação às mudanças climáticas: um caso ilustrativo. Revista Econômica do Nordeste, v. 50, n. 1, p. 65 83, 2019. 